\title{
Cases of HIV testing among pregnant women attending antenatal care during COVID-19 pandemic: analysis of data surveillance
}

\author{
Fitriana Kurniasari Solikhah \\ Poltekkes Kemenkes Malang, East Java, Indonesia
}

\begin{abstract}
Introduction: During COVID-19 pandemic, human immunodeficiency virus (HIV) test surveillance of pregnant women visiting antenatal care (ANC) clinics was used to estimate participation of pregnant women in HIV testing. Socio-demographic recording of HIV patients was conducted to gain a better knowledge of the disease profile, and to aid into the development of more effective HIV prevention and care strategies. Demographic studies of pregnant women who test positive for HIV can serve as proxies for targeted HIV interventions in a wider community as well as mother-to-child transmission prevention.

Material and methods: A total of 607 pregnant women, aged 15-49 years, who first visited ANC clinic during a period of January-March 2020 were enrolled. Samples were gathered for three months, or until target sample size was met. Chi-square test was performed to determine various age factors. Link between demographic characteristics and risk of HIV infection was determined using logistic regression approach with SPSS version 26.0.

Results: Overall, no demographic variables were found to be substantially associated with HIV prevalence. However, research on demographic characteristics, history of HIV testing, and COVID-19 pandemic revealed that the most conducted tests were among young, less educated, primigravida, and rural women with poor socio-economic status.

Conclusions: There is a relationship between parity, employment status, education level, and age and HIV testing among pregnant women during the COVID-19 pandemic.
\end{abstract}

HIV AIDS Rev 2022; 21, 1: 31-36

DOI: https://doi.org/10.5114/hivar.2022.113388

Key words: pregnant women, HIV testing, rural population, COVID-19.

\section{Introduction}

Human immunodeficiency virus (HIV) is one of the leading causes of mortality among infected individuals. Prevention of mother-to-child transmission (MTCT) initiative is being developed to stop HIV transmission. HIV/acquired immunodeficiency syndrome (AIDS) screening is a very successful technique for preventing transmission. In an effort to avoid
HIV transmission from mother-to-child, knowing pregnant woman's HIV status enables her to initiate an urgent MTCT prevention program (PPIA). HIV counseling and testing are also included as a starting point in UNAIDS' approach for 'getting to zero' [1].

The Indonesian Ministry of Health has a program for determining $90 \%$ of HIV status, followed by $90 \%$ of persons 
living with HIV obtaining antiretroviral (ARV) medication, hence suppressing $90 \%$ of the virus in the population and preventing it from infecting others. Along with a reduction in HIV case detections, a decline in HIV and other illness screenings for pregnant women occurred in 2020. The program to prevent mother-to-child infectious illnesses, such as HIV, syphilis, and hepatitis, targeting at 2.5 million tests per year, has examined just 1.7 million pregnant women throughout the 2020 pandemic period [2]. According to findings from interviews with ten pregnant women in a village, ten persons (100\%) expressed fear of going for a pregnancy check-up, let alone taking an HIV test, during the COVID-19 epidemic.

Elimination of MTCT of HIV remains an important goal of the Centers for Disease Control and Prevention and other international public health organizations [3]. With comprehensive perinatal HIV care, the risk of MTCT of HIV can be reduced from $25 \%$ to less than $1 \%$. This in-depth risk reduction requires antenatal knowledge of HIV status, so that prevention strategies can be implemented [4]. Although all women are recommended to be tested for HIV in pregnancy, not all pregnant women with HIV would be identified through early universal screening, if they were exposed to HIV during pregnancy and subsequently seroconverted [5].

HIV testing for pregnant women benefits pregnant women's safety, because it empowers them as well as their partners [6] in avoiding HIV and AIDS transmission, particularly from mother-to-child. Identifying HIV instances in the community is critical, so that persons with infectious illnesses may be rapidly diagnosed and treated, preventing HIV from progressing to AIDS in those whose health status deteriorates [7].

Apart from estimating participation of pregnant women in HIV testing and developing HIV intervention strategies, ANC data analysis can provide valuable insight into socio-demographic characteristics of HIV-positive pregnant women, resulting in indicators, such as target groups for HIV interventions in the general population and measures to ensure complete prevention of MTCT [8]. Socio-demographic recording of HIV patients was conducted to gain a better knowledge of the disease profile, and to aid in the development of more effective HIV prevention and care strategies. Therefore, this article focused on the socio-demographic characteristics of pregnant women at increased risk of infection and investigated pregnant women's utilization of ANC services and HIV testing to accomplish comprehensive MTCT.

\section{Material and methods}

\section{Ethical aspects}

The Research Ethics Committee of a teaching institution approved the research project according to the recommendations of resolution 279/VIII/2021 from the National Council of Health. All participants signed an informed consent form.

\section{Design, period, and place of study}

The present research is a cross-sectional study that employed sequential sampling, anonymous testing methodologies, and two standardized assay protocols. To minimize selection bias, all eligible pregnant women were recruited sequentially in the order they attended ANC. To ensure quality of the data, data collection was limited to the first twenty qualified responders on-site at any given day.

\section{Sample's population and inclusion and exclusion criteria}

The study population comprised all pregnant women aged 15 to 49 years, who attended a designated ANC care center in Malang for the first time throughout the monitoring period. Between January and March 2020, data and samples were gathered for three months, or until the target sample size was achieved. At least two guard sites per district are chosen, preferably one urban and one rural. A total of 607 respondents from Wonokerto, Malang, Indonesia were included in the sample.

\section{Procedures}

All respondents who fulfilled the criteria, provided information on their socio-demographic characteristics and HIV test/ART status as well as blood samples. The following information were gathered from respondents: 1) age; 2) literacy status; 3) gravida; 4) pregnancy duration; 5) source of reference; 6) current place of residence; 7) length of stay at current residence; 8) current occupation; 9) current employment of respondent's husband, and 10) migration status of spouse. Additionally, variables were created to examine socio-demographic characteristics. Observed trend among pregnant women was believed to represent a broader trend in the disease population. Surveillance techniques were rules and standards, which specified how data/ sample collection and subsequent testing were conducted by qualified professionals.

\section{Analysis of results and statistics}

Descriptive statistics were used to characterize the study sample's characteristics. Chi-square test was performed to determine various age factors. A relationship between demographic characteristics and risk of HIV infection was determined using a logistic regression approach. SPSS version 26.0 was used to analyze the data.

\section{Results}

The participation of pregnant women in HIV testing during the COVID-19 pandemic was $18.2 \%$, and majority of pregnant women did not present for HIV testing for prevention $(81.8 \%)$. 
Table 1. Distribution by category of participation of pregnant women in HIV testing $(N=607)$

\begin{tabular}{|c|c|c|}
\hline Demographic variables (category) & $n$ & $\%$ \\
\hline \multicolumn{3}{|l|}{ Age (in years) } \\
\hline $15-24$ & 356 & 58.6 \\
\hline $25-49$ & 251 & 41.4 \\
\hline \multicolumn{3}{|l|}{ Literacy status } \\
\hline Illiterate & 225 & 37.0 \\
\hline Literate up to standard 5 & 340 & 56.0 \\
\hline Literate standard 6-10 & 26 & 4.1 \\
\hline Literate post-graduation & 16 & 2.6 \\
\hline \multicolumn{3}{|l|}{ Order of current pregnancy } \\
\hline First & 299 & 49.2 \\
\hline Second & 224 & 36.9 \\
\hline Third & 21 & 3.5 \\
\hline Fourth or more & 63 & 10.4 \\
\hline \multicolumn{3}{|l|}{ Job status } \\
\hline Housewives & 387 & 63.7 \\
\hline Work & 220 & 36.2 \\
\hline \multicolumn{3}{|l|}{ Duration of current pregnancy } \\
\hline First trimester & 292 & 48.2 \\
\hline Second trimester & 224 & 36.9 \\
\hline Third trimester & 91 & 14.9 \\
\hline \multicolumn{3}{|l|}{ Source of referral to ANC clinic } \\
\hline Self-referral & 13 & 2.2 \\
\hline Family/friends & 17 & 2.8 \\
\hline NGO & 5 & 0.8 \\
\hline Private healthcare provider & 183 & 30.2 \\
\hline Government healthcare provider & 306 & 50.4 \\
\hline ICTC/ART center & 83 & 13.6 \\
\hline \multicolumn{3}{|c|}{ Current occupation of respondent's spouse } \\
\hline Student & 0 & 0.0 \\
\hline Not applicable & 1 & 0.2 \\
\hline Unemployed & 1 & 0.2 \\
\hline Domestic servant & 2 & 0.3 \\
\hline Large business/self employed & 8 & 1.3 \\
\hline Agricultural cultivator & 9 & 1.4 \\
\hline Hotel staff & 14 & 2.3 \\
\hline Truck driver/helper & 39 & 6.4 \\
\hline Petty business/small shop owner & 50 & 8.2 \\
\hline Local transport worker & 49 & 8.0 \\
\hline Agricultural laborer & 65 & 10.7 \\
\hline Government or private service & 66 & 11.8 \\
\hline Non-agricultural laborer & 101 & 16.6 \\
\hline Skilled/semi-skilled worker & 202 & 33.2 \\
\hline
\end{tabular}

Table 2. Distribution of participation of pregnant women in HIV testing during the COVID-19 pandemic, 2020

\begin{tabular}{l|c|c}
\hline Variable & $n$ & $\%$ \\
\hline \multicolumn{2}{|c|}{ Participation of pregnant women in HIV testing } \\
\cline { 2 - 3 } Not participating & 356 & 81.8 \\
\hline Participating & 251 & 18.2 \\
\hline Total & 607 & 100.0 \\
\hline
\end{tabular}

\section{Socio-demographic profile of pregnant women attending ANC clinics in Malang}

Analysis of factors participation of pregnant women in HIV testing provided insight into perceptions and levels of HIV awareness among pregnant women in Malang. The participation of pregnant women in HIV testing was higher among ANC mothers aged between 15 to 24 years (62\%) compared to mothers aged 15-24 years (38\%). The participation of pregnant women in HIV testing among highly educated women (53\%) was comparable to those without education (10.5\%). The involvement of pregnant women in HIV testing was higher in primigravida $(42.7 \%)$ than multi-gravida $(3.7 \%)$. Based on the respondent's occupation, significance $(28 \%)$ was noted among workers (agricultural, non-agricultural, skilled, semi-skilled) who represented the low-income category. A significantly higher participation of pregnant women in HIV testing (7.9\%) was observed among ANC mothers, who indicated that their partner's occupation was a truck driver, local transportation worker, hotel staff, or those who were migrants (bridge dwellers). The consolidated results categorized into socio-demographic variables are presented in Table 1.

\section{Socio-demographic profile of pregnant women who were tested for HIV and who visited the ANC clinic}

Demographics of pregnant women who were tested for HIV were investigated. Women themselves identified vulnerable groups to understand their patterns of disease transmission. However, an in-depth analysis of the demographics of pregnant women tested for HIV revealed a more limited pattern of disease, very different from an overall ANC-HIV pattern. Of the 607 respondents, education up to secondary level or lower (37.0\%) and primigravida (49.2\%) were most significant. Most of the pregnant women tested for HIV were housewives (63.7\%). Most of the spouses occupations related to low-income job categories, including laborers, workers, small shop owners (33.2\%), and transportation workers $(8.0 \%)$ (Table 2). The respondents were divided into 2 age groups of participants and non-participants, because participation was also a qualifying criterion. Among 
Table 3. Analysis of participants' data

\begin{tabular}{|c|c|c|c|c|c|c|c|}
\hline \multirow[t]{3}{*}{ Variables } & \multicolumn{6}{|c|}{ Participation of pregnant women in HIV testing } & \multirow[t]{3}{*}{$p$-value } \\
\hline & \multicolumn{2}{|c|}{ Participate } & \multicolumn{2}{|c|}{ Not participate } & \multicolumn{2}{|c|}{ Total } & \\
\hline & $n$ & $\%$ & $n$ & $\%$ & $n$ & $\%$ & \\
\hline \multicolumn{8}{|l|}{ Age (in years) } \\
\hline $15-24$ & 112 & 18.4 & 244 & 40.2 & 356 & 58.6 & \multirow[t]{2}{*}{$<0.001$} \\
\hline $25-49$ & 2 & 0.3 & 249 & 41.0 & 251 & 4.4 & \\
\hline \multicolumn{8}{|l|}{ Literacy status } \\
\hline Illiterate & 50 & 8.2 & 175 & 28.8 & 225 & 37.0 & \multirow[t]{4}{*}{0.022} \\
\hline Literate up to standard 5 & 64 & 10.5 & 276 & 45.5 & 340 & 56.0 & \\
\hline Literate standard 6-10 & 0 & 0.0 & 26 & 4.3 & 26 & 4.1 & \\
\hline Literate post-graduation & 0 & 0.0 & 16 & 2.6 & 16 & 2.6 & \\
\hline \multicolumn{8}{|l|}{ Order of current pregnancy } \\
\hline First & 297 & 48.9 & 2 & 0.3 & 299 & 49.2 & \multirow[t]{4}{*}{$<0.001$} \\
\hline Second & 108 & 17.8 & 116 & 19.1 & 224 & 36.9 & \\
\hline Third & 4 & 0.7 & 17 & 2.8 & 21 & 3.5 & \\
\hline Fourth or more & 3 & 0.5 & 60 & 9.9 & 63 & 10.4 & \\
\hline \multicolumn{8}{|l|}{ Duration of current pregnancy } \\
\hline First trimester & 83 & 13.7 & 304 & 50.1 & 292 & 48.2 & \multirow[t]{3}{*}{0.03} \\
\hline Second trimester & 31 & 5.1 & 189 & 31.1 & 224 & 36.9 & \\
\hline Third trimester & 10 & 1.6 & 53 & 8.7 & 63 & 14.9 & \\
\hline \multicolumn{8}{|l|}{ Source of referral to ANC clinic } \\
\hline Self-referral & 8 & 1.3 & 6 & 0.9 & 13 & 2.2 & \multirow[t]{6}{*}{0.07} \\
\hline Family/friends & 7 & 1.2 & 10 & 1.6 & 17 & 2.8 & \\
\hline NGO & 1 & 0.2 & 4 & 0.6 & 5 & 0.8 & \\
\hline Private healthcare provider & 114 & 4.4 & 69 & 11.4 & 183 & 30.2 & \\
\hline Government healthcare provider & 250 & 18.8 & 56 & 9.2 & 306 & 50.4 & \\
\hline ICTC/ART center & 50 & 8.2 & 33 & 5.4 & 83 & 13.6 & \\
\hline \multicolumn{8}{|l|}{ Current occupation of respondent's spouse } \\
\hline Student & 0 & 0.0 & 0 & 0.0 & 0 & 0.0 & \multirow[t]{14}{*}{0.09} \\
\hline Not applicable & 1 & 0.2 & 0 & 0.0 & 1 & 0.2 & \\
\hline Unemployed & 1 & 0.2 & 0 & 0.0 & 1 & 0.2 & \\
\hline Domestic servant & 2 & 0.3 & 0 & 0.0 & 2 & 0.3 & \\
\hline Large business/self employed & 3 & 0.5 & 5 & 0.8 & 8 & 1.3 & \\
\hline Agricultural cultivator & 5 & 0.8 & 4 & 0.6 & 9 & 1.4 & \\
\hline Hotel staff & 11 & 1.8 & 3 & 0.5 & 14 & 2.3 & \\
\hline Truck driver/helper & 27 & 4.4 & 12 & 1.9 & 39 & 6.4 & \\
\hline Petty business/small shop owner & 44 & 7.2 & 6 & 0.9 & 50 & 8.2 & \\
\hline Local transport worker & 32 & 4.6 & 17 & 2.8 & 49 & 8.0 & \\
\hline Agricultural laborer & 58 & 9.5 & 7 & 0.5 & 65 & 10.7 & \\
\hline Government or private service & 53 & 8.7 & 13 & 2.2 & 66 & 11.8 & \\
\hline Non-agricultural laborer & 71 & 11.7 & 30 & 4.9 & 101 & 16.6 & \\
\hline Skilled/semi-skilled worker & 140 & 23.0 & 62 & 10.2 & 202 & 33.2 & \\
\hline
\end{tabular}

${ }^{*}$ Significantly different at $5 \%$ level $(p<0.05)$. ${ }^{*}$ Significantly different at $0.5 \%$ level $(p<0.005)$. ${ }^{* * *}$ Significantly different at $0.1 \%$ level $(p<0.001)$ 
the group of participants, the highest proportion $(n=81.4 \%)$ of the respondents were primigravida, while in the group of non-participants, the highest proportion was secondary. Participation of pregnant women in HIV testing among primigravida women was also a proxy indicator for new infections. A significantly higher prevalence was observed among primigravida women aged between 25 and 49 years $(41.4 \%$, $p<0.001)$.

\section{Discussion}

Investigating the prevalence of HIV testing among pregnant women in Malang based on the analysis of socio-demographic factors of ANC participants, no factors were significantly associated with the risk of HIV infection (Table 1). Age-specific analyzes showed that the prevalence of HIV testing was significantly higher among pregnant women aged between 25 and 49 years compared with those aged between 15 and 24 years (Table 3). The lower HIV prevalence among young mothers is in line with a downward trend in the prevalence of adult HIV testing nationally [9]. This may be due to an increased awareness about HIV and considerable decline in high-risk behaviors among the younger generation, especially men, which reduce the risk of HIV transmission [10]. Education, economic status, or place of residence had no significant effect on overall state-level of HIV prevalence [11]. However, with a focus on the socio-demography of pregnant women, HIV testing of pregnant women has become the main prevention of HIV transmission and tracking of people at risk [12].

Among the respondents, the higher proportion was young age, literate to or below the middle level, living in rural areas, being housewives, and living with partners who fall into bridge population/low income category (Table 2). With respect to occupation (both respondents and their partners), a detention of epidemics in agricultural and non-farm workers was noted [13].

In addition, the trend of decreasing HIV prevalence among pregnant women visiting antenatal care clinics, disguises the limited susceptibility to HIV infection in Malang. These data emphasize the need to distribute HIV prevention programs to adults with low education from rural areas and low economic backgrounds, with a particular focus on housewives, agricultural and non-agricultural workers, transport workers, and seasonal migrants. Available ANC services, history of HIV testing, monitoring of CD4 cells and providing mentoring for the use of ART are very helpful for those who are HIV positive [14].

\section{Status of prevention of transmission of HIV/AIDS from mother-to-child}

One of the health service products provided by Puskesmas is the prevention of MTCT, specifically the prevention of MTCT of HIV. MTCT consists of 4 service activities, namely HIV transmission at reproductive age, prevention of unplanned pregnancy in HIV-positive mothers, prevention of HIV transmission from HIV-positive pregnant women to their unborn babies, and ensuring psychological, social, and care support to HIV-positive mothers, their children, and families. During the COVID-19 pandemic, there was a decline (around 27.6\%) of pregnant women who did not previously used ANC services, and about $37.8 \%$ had never been tested for HIV. Possible causes included first pregnancy, first trimester of the current pregnancy (Table 1) as well as fear of contracting COVID-19. However, among the respondents, there were women who did not wanted to receive ANC services in the first trimester [15]. Approximately $36.4 \%$ were multi-gravida women, thus posing a serious threat of horizontal and vertical HIV transmission. This suggests the possibility of these women becoming seroconverted during subsequent pregnancies and underscores the need for HIV retesting during late pregnancy [16].

The success of prevention of parent-to-child transmission (PPTCT) programs depends on a cumulative impact of attrition of mother-to-child pairs at each step of PPTCT cascade, which includes a series of interventions, with attending antenatal care, HIV testing, and accepting and adhering to antiretroviral drug prophylaxis for themselves and their exposed infant. Only $15-30 \%$ of pairs in high-burden countries complete the cascade. In our study, the cascade until delivery was completed by $21.0 \%$ pairs (ART in ANC for $\geq 24$ weeks) and $40.7 \%$ under ART in ANC for $\geq 12$ weeks. A higher coverage was reported in a study from Brazil, where $52.7 \%$ of newborns in the cohort benefited from a complete package of interventions under prevention of mother-tochild transmission (PMTCT). The Mumbai PMTCT model is highly successful in terms of linking all HIV seropositive pregnant women to ART centers, and thereby initiation of ART, with observed time of about a week. A study in Kenya shows that this linkage of time can be reduced to zero with integration of HIV treatment services of antenatal care.

To achieve the 95-95-95 goal by 2030 and PPTCT, we suggested to reach out to young mothers, especially from less educated and low-income backgrounds in Malang, and distribute information regarding HIV testing in ANC during the COVID-19 pandemic in every possible way [17]. Mandating RCH registration at Puskesmas to obtain a birth certificate, as it was done in Malang [18], might increase the proportion of those who access ANC services, which in turn would reflect HIV testing. Simultaneously, although HIV testing has been performed by default in all ANC centers, the question arises whether mothers and family members are aware of information regarding HIV testing during the pandemic and its' follow-up [19]. It is therefore important that all pregnant women undergoing HIV testing during the COVID-19 pandemic are well-informed about the test and its' implications as well as through pre-test counseling for a productive response [20]. Appropriate pre- and posttest counseling, and state-level ART follow-up, with a psychological support to infected pregnant women and their family members, are all important for continuing adherence to ART [21]. Health workers provide policy strategies to suc- 
ceed in simultaneous HIV testing programs in implementation of ANC as an effort to prevent MTCT of HIV-AIDS.

\section{Conclusions}

There was a relationship between parity, employment status, education level, and age among pregnant women in HIV testing. Housewives with their first pregnancy, age between 15 and 24 are more indifferent to joining ANC HIV sentinel surveillance.

\section{Conflict of interest}

The author declares no conflict of interest.

\section{References}

1. Santhakumar A, Ganesh B, Malathi M, Kumar P, Rajan S, Elangovan A. Confined vulnerability of HIV infection among pregnant women attending antenatal care clinics in Karnataka, India: analysis of data from the HIV sentinel surveillance 2017. Clin Epidemiol Global Health 2020; 8: 1127-1133.

2. Kim LH, Rodriguez MI, Cohan D, Caughey AB. Should pregnant women have repeat HIV testing at 24 weeks or 35 weeks gestational age to maximally reduce vertical transmission? Am J Obstet Gynecol 2011; 204: S252.

3. Aditya RS, Yusuf A, Solikhah FK, et al. The experience of nurses in handling business class patient in commercial medical escort in Indonesia. Syst Rev Pharm 2020; 11: 119-124.

4. Kotijah S, Yusuf A, Aditya RS, Solikhah FK, Mosteiro P. Development of social support model to reduce menopause women's anxiety. Ansiedad y Estrés 2021; 27: 81-88.

5. Yusuf A, Aditya RS, Yunitasari E, Aziz AN, Solikhah FK. Experience of persons affected by leprosy in facing psychosocial problems: a qualitative method. Syst Rev Pharm 2020; 11:219-223.

6. Ahmadi M, Rahimi F, Rosta F, AlaviMajd H, Valiani M. Effect of progressive muscle relaxation training on postpartum blues in high-risk pregnant women. Journal of Holistic Nursing and Midwifery 2019; 29: 192-199.

7. Dowdy DL. Development of a guidebook for teens with PCOS. J Obstet Gynecol Neonatal Nurs 2011; 40: S2.

8. Rueda S, Mitra S, Chen S, et al. Examining the associations between HIV-related stigma and health outcomes in people living with HIV/ AIDS: a series of meta-analyses. BMJ Open 2016; 6: e011453. DOI: 10.1136/bmjopen-2016-011453.

9. Yeung MW, Young J, Moodie E, et al. Changes in quality of life, healthcare use, and substance use in HIV/hepatitis C coinfected patients after hepatitis $\mathrm{C}$ therapy: a prospective cohort study. HIV Clin Trials 2015; 16: 100-110.

10. Sasono TN. Peran Warga Peduli Aids Cahaya Care Turen Dalam Meningkatkan Kualitas Hidup Odha. Jurnal Kesehatan Mesencephalon 2017; 3: 51-54. DOI: 10.36053/mesencephalon.v3i1.37.

11. Stringhini S, Carmeli C, Jokela $\mathrm{M}$, et al. Socioeconomic status and the $25 \times 25$ risk factors as determinants of premature mortality: a multicohort study and meta-analysis of 1.7 million men and women. Lancet 2017; 389: 1229-1237.

12. Permana RTR. Peer Group Terhadap Sikap Remaja Tentang HIV/ AIDS Di Sma N 2 Bantul Peer Group Terhadap Sikap Remaja Tentang Hiv/Aids Di Sma N 2 Bantul. Skripsi thesis, STIKES Aisyiyah Yogyakarta; 2014.

13. Earnshaw VA, Bogart LM, Dovidio JF, Williams DR. Stigma and racial/ethnic HIV disparities: moving toward resilience. American Psychologist 2013; 68: 225-236.
14. Link BG, Phelan JC. Conceptualizing stigma. Ann Rev Sociol 2001; 27: 363-385.

15. Alam M, Zayed R. Prevalence and determinants of body dissatisfaction among post-partum Arab women in Qatar. Value in Health 2018; 21: S59. DOI: 10.1016/j.jval.2018.07.450.

16. Miller LM, Lampe JW, Newton KM, et al. Being overweight or obese is associated with harboring a gut microbial community not capable of metabolizing the soy isoflavone daidzein to O-desmethylangolensin in peri- and post-menopausal women. Maturitas 2017; 99: 37-42.

17. Nagpal S, Chandrashekarappa S, Chakrashali S, Rakshitha J, Mysore Ramaiah NM. Exploring the hidden part of the iceberg: post-partum weight retention among mothers and its association with sociodemographic, cultural and behavioural factors. Clin Epidemiol Global Health 2020; 9: 62-68.

18. Laela S, Keliat BA, Mustikasari. Thought stopping and supportive therapy can reduce postpartum blues and anxiety parents of premature babies. Enfermeria Clinica 2018; 28: 126-129.

19. Robles M, Dubois C, Gautier C, et al. Maternal parity affects placental development, growth and metabolism of foals until 1 year and a half. Theriogenology 2018; 108: 321-330.

20. Kurniati Y, Sinrang W, Syamsuddin S. Postpartum blues syndrome: serum zinc and psychosocial factors. Enfermeria Clinica 2020; 30: 18-21.

21. Bass III PF, Bauer NS. Parental postpartum depression: more than 'baby blues'. Contemporary Pediatrics 2018; 35: 35-38. 